Erratum

\title{
Erratum to “Quadratic Integral Sliding Mode Control for Nonlinear Harmonic Gear Drive Systems with Mismatched Uncertainties"
}

\author{
Runze Ding and Lingfei Xiao \\ College of Energy and Power Engineering, Nanjing University of Aeronautics and Astronautics, Nanjing, China \\ Correspondence should be addressed to Lingfei Xiao; lfxiao@nuaa.edu.cn
}

Received 28 April 2020; Accepted 29 April 2020; Published 17 July 2020

Copyright (c) 2020 Runze Ding and Lingfei Xiao. This is an open access article distributed under the Creative Commons Attribution License, which permits unrestricted use, distribution, and reproduction in any medium, provided the original work is properly cited.

In the article titled "Quadratic Integral Sliding Mode Control for Nonlinear Harmonic Gear Drive Systems with Mismatched Uncertainties" [1], an additional reference should have been cited, which is included in the text below, as reference 19 [2]. Accordingly, the sentence referring to Equation (18) in Section 3, "Quadratic Integral Sliding Mode Design," should read as follows:

In order to compensate for the effect of mismatched uncertainties, the quadratic integral sliding mode surface is designed as in [19].

\section{References}

[1] R. Ding and L. Xiao, "Quadratic integral sliding mode control for nonlinear harmonic gear drive systems with mismatched uncertainties," Mathematical Problems in Engineering, vol. 2018, Article ID 2372305, 18 pages, 2018.

[2] X. Zhang, "Integral sliding mode control for non-linear systems with mismatched uncertainty based on quadratic sliding mode," The Journal of Engineering, vol. 2015, no. 4, pp. 154-159, 2015. 